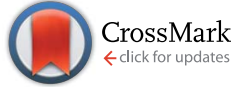

Cite this: J. Mater. Chem. A, 2015, 3, 1632

Received 14th November 2014 Accepted 26th November 2014 DOI: 10.1039/c4ta06191h

www.rsc.org/MaterialsA

\section{Electrospinning of recycled PET to generate tough mesomorphic fibre membranes for smoke filtration $\uparrow$}

\author{
I. N. Strain, ${ }^{a}$ Q. Wu, ${ }^{\text {b }}$ A. M. Pourrahimi, ${ }^{\text {b }}$ M. S. Hedenqvist, ${ }^{\text {b }}$ R. T. Olsson ${ }^{\star b}$ \\ and R. L. Andersson*b
}

Tough fibrous membranes for smoke filtration have been developed from recycled polyethylene terephthalate (PET) bottles by solution electrospinning. The fibre thicknesses were controlled from 0.4 to $4.3 \mu \mathrm{m}$ by adjustment of the spinning conditions. The highest fibre strength and toughness were obtained for fibres with an average diameter of $1.0 \mu \mathrm{m}, 62.5 \mathrm{MPa}$ and $65.8 \mathrm{MJ} \mathrm{m}^{-3}$, respectively. The Xray diffraction (XRD) patterns of the fibres showed a skewed amorphous halo, whereas the differential scanning calorimetry (DSC) results revealed an apparent crystallinity of $6-8 \%$ for the 0.4 and $1 \mu \mathrm{m}$ fibres and $0.2 \%$ crystallinity for the $4.3 \mu \mathrm{m}$ fibres. Heat shrinkage experiments were conducted by exposing the fibres to a temperature above their glass transition temperature $\left(T_{\mathrm{g}}\right)$. The test revealed a remarkable capability of the thinnest fibres to shrink by $50 \%$, which was in contrast to the $4.3 \mu \mathrm{m}$ fibres, which displayed only $4 \%$ shrinkage. These thinner fibres also showed a significantly higher glass transition temperature $\left(+15^{\circ} \mathrm{C}\right)$ than that of the $4.3 \mu \mathrm{m}$ fibres. The results suggested an internal morphology with a high degree of molecular orientation in the amorphous segments along the thinner fibres, consistent with a constrained mesomorphic phase formed during their rapid solidification in the electric field. Air filtration was demonstrated with cigarette smoke as a model substance passed through the fibre mats. The $0.4 \mu \mathrm{m}$ fibres showed the most effective smoke filtration and a capacity to absorb $43 \times$ its own weight in smoke residuals, whereas the $1 \mu \mathrm{m}$ fibres showed the best combination of filtration capacity $(32 \times)$ and mechanical robustness. The use of recycled PET in the form of nanofibres is a novel way of turning waste into higher-value products.

\section{Introduction}

Useful recycling of plastic polymer waste is a growing concern over the entire globe. In the United States in 2012, 32 million tons of plastic waste were generated, amounting to $12.7 \%$ by weight of the total municipal solid waste, ${ }^{\mathbf{1}}$ but about twice that if considering the volume. ${ }^{2}$ Only $9 \%$ of this plastic waste was recovered for recycling, ${ }^{1} \mathrm{ca}$. $30 \%$ of which was related to the collection of used poly(ethylene terephthalate) (PET) bottles. ${ }^{3}$ These post-consumer PET bottles are nowadays highly valued in manufacturing since they are inexpensive compared to virgin PET, which would have an equivalent market price of $c a .150$ million USD if no PET would be recycled in the USA. ${ }^{4}$ The

${ }^{a}$ University of Illinois at Urbana-Champaign, Department of Chemical \& Biomolecular Engineering, 114 Roger Adams Laboratory, MC 712, 600 South Mathews Avenue, Urbana, IL 61801, USA

${ }^{b}$ KTH Royal Institute of Technology, School of Chemical Science and Engineering, Fibre and Polymer Technology, 10044 Stockholm, Sweden.E-mail: riander@kth.se; rols@ kth.se; Fax: +468 208856; Tel: +468 7909426; +46 87907637

$\uparrow$ Electronic supplementary information (ESI) available: Video of smoke adsorption testing. See DOI: 10.1039/c4ta06191h current market for recycled PET ranges from engineering plastics, automobiles, packaged foods, containers, fleece fabric, and different kinds of film., ${ }^{5,6}$ However, virgin PET also has additional use in applications such as protective clothing, membranes, vascular grafts, tissue scaffolding, and filtration. ${ }^{6,7}$ Thus, recycled PET could be an ideal cost-effective choice in a variety of applications.

Bottle-grade PET exists as a semi-crystalline thermoplastic with high impact and tensile strength, chemical resistance, and a reasonable thermal stability, ${ }^{\mathbf{8} 9}$ but since recycled PET has been in contact with a variety of substances and environments, applications in a biological setting are not suitable. This fact, in addition to the growing concerns on environmental air pollution, ${ }^{10}$ means that filtration is one of the most promising application for recycled ultrathin PET fibres. Nonwoven fabrics of PET could here play a momentous role in dust filtration because of their porous structure and low cost of manufacturing in combination with its unique mechanical properties. ${ }^{10}$ Utilization of recycled PET bottles for the manufacture of profitable filtration products would help to offset the cost of recycling and encourage the collection of post-consumer PET bottles. The PET polyester is also particularly marketable for recycling since it is 
one of the most easily identifiable thermoplastics since almost all beverage bottles are made of PET.

An increasingly popular technique for the production of nonwoven membranes is electrospinning, which is one of the most rapidly growing industrial polymer processing methods for the production of ultrathin fibres. Studies on the electrospinning of PET exist, but only one published study concerns the electrospinning of recycled PET, ${ }^{9}$ where electrospinning from melt was applied to prepare $c a .30 \mu \mathrm{m}$ thick fibres. Polymer melt spinning is a useful technique to handle thermoplastics when traces of other plastics are possibly present as long as the polymers show melt characteristics that enable them to mix properly at a given process temperature. The drawback is the considerable amounts of heat (energy) required to process the material, and the inferior mechanical properties that comes from repeated heating cycles. ${ }^{11,12}$ Another limitation of the electrospinning of polymer melts is the relatively high viscosity of the spun material, making it difficult to produce very thin uniform fibres. ${ }^{13}$ A possible alternative advantageous method would be to carry out the electrospinning of recycled PET from solvents, since it allows for unprecedented control of fibre morphology. The solvents could be recycled by process-coupled condensation units, with the additional cost for this offset by the thermal energy savings and the benefits of separation of fillers after precipitation and sedimentation.

In this present study, solvent-based electrospinning was used to produce recycled PET micro- and nanofibres for application-oriented research. The possibility of producing large quantities of continuous ultrafine fibres with a thickness $c a .2$ orders of magnitude smaller than previously reported is shown. ${ }^{14}$ Fibre morphology and mean diameter were studied in relation to the flow rate and concentration of recycled PET. The electrospun fibre properties were determined by cold-fieldemission scanning electron microscopy (FE-SEM), infrared spectroscopy (IR), tensile testing, X-ray diffraction (XRD), and differential scanning calorimetry (DSC). The prepared fibres were collected as aligned fibre mats for mechanical testing in a micromechanical stage, and as randomly oriented fibres in isotropic fibre mats. The fibre mats were demonstrated as filters for airborne substances such as polycyclic aromatic hydrocarbons (PAH), persistent organic pollutant (POP) and fine particulate matter (nanoparticles) since the effect of these in our environment is a current concern. ${ }^{15}$ In this study cigarette smoke was chosen as a model substance, as it contains several thousands of components, which includes PAH, POP and $c a$. $5 \%$ particulate matter. ${ }^{16,17}$ The results pave the way for supplementary studies on the optimization of these ultrafine membranes for use in nanofiltration and other applications in consumer and industrial products.

\section{Experimental}

\section{Preparation of polymer solution for electrospinning}

Recycled polyethylene terephthalate (PET) was obtained from Coca Cola bottles $(500 \mathrm{~mL})$ collected from the same production batch (Coca-Cola Enterprises Sweden AB). The PET bottles were produced from at least $99.8 \mathrm{wt} \%$ PET without plasticizers, as determined from the data-sheet from the manufacturer. The molecular weight of this type of PET, which is commonly used during the production of PET bottles, typically lies in the range of 30-80 kDa. ${ }^{8}$ All the bottles were cleaned and rinsed with pure ethanol prior to drying, followed by shredding into $5 \times 5 \mathrm{~mm}^{2}$ small pieces. Trifluoroacetic acid (TFA, Reagent Plus, 99\%) was purchased from Sigma-Aldrich and dichloromethane (DCM, ACS Grade Stabilized, 99.5\%) was purchased from VWR International. A mixture of TFA and DCM in a ratio $70 / 30$ by weight was prepared. The recycled PET was then added to the solvent mixture at concentrations of 10,15 , and $20 \mathrm{wt} \%$. Solutions were mixed for $24 \mathrm{~h}$ to ensure complete dissolution of the PET at a temperature of $20^{\circ} \mathrm{C}$.

\section{Electrospinning of unaligned fibres}

The polymer solutions were fed at different rates $(20,10$ and $5 \mu \mathrm{L} \mathrm{min}^{-1}$ ) from a $5 \mathrm{~mL}$ solvent resistant syringe through a polytetrafluoroethylene tube attached to a steel needle (inner diameter $0.60 \mathrm{~mm}$ ) mounted $25 \mathrm{~cm}$ above the collection plate. An electric potential between 7 and $12 \mathrm{kV} \mathrm{m}^{-1}$ (depending on the concentration of PET and flow rate) was applied by adjusting the voltage from the needle to the collection plate. The faster the flow rate, the greater was the voltage required for spinning. ${ }^{18}$ All samples were spun for 20 min to ensure that a substantial amount of fibres could be obtained for FE-SEM and IR-spectroscopy analysis.

\section{Electrospinning of aligned fibres}

The preparation of the aligned fibres was identical with that of the unaligned fibres except that solutions were fed at a fixed flow rate and voltage. The 10 and $15 \mathrm{wt} \%$ PET concentrations were spun with a flow rate of $5 \mu \mathrm{L} \mathrm{min}^{-1}$, whereas the $20 \mathrm{wt} \%$ concentration was spun with a flow rate of $10 \mu \mathrm{L} \mathrm{min}{ }^{-1}$, as these conditions gave the most uniform fibres. The fibres were collected on a rotating alignment drum (diameter $=50 \mathrm{~mm}$ ) rotating at $2000 \mathrm{rpm}$ at the same spinning distance $(25 \mathrm{~cm})$ as the unaligned fibres. The total spin time was varied depending on the PET concentration of the sample ( $10 \mathrm{wt} \%$ spun for $4 \mathrm{~h}$, $15 \mathrm{wt} \%$ for $2 \mathrm{~h}$, and $20 \mathrm{wt} \%$ for $1 \mathrm{~h}$ ) in order to produce fibre mats of similar thicknesses.

\section{Tensile testing}

Fig. 1 shows the micromechanical tensile testing stage with a mounted PET fibre mat. The tensile tests were performed according to a previously reported Template Transfer Method (TTM). ${ }^{19,20}$

Four pieces of fluorinated ethylene propylene release films (thickness $=76 \mu \mathrm{m}$ ) were first secured along the centre of the alignment drum. Aluminium foil templates (thickness $=30 \mu \mathrm{m}$ ) with a cut out window (length $=5 \mathrm{~mm}$, width $=10 \mathrm{~mm}$ ) were then attached over the release films, which were attached to the drum with copper tape (thickness $=66 \mu \mathrm{m}$ ). The cut-out window allowed fibre testing on a Deben Microtest micromechanical stage (Fig. 1). Before removal from the alignment drum, fibres were fixed to both sides of the window using alkoxy-ethylcyanoacrylate (Loctite 460, Hennkel AG \& Co. KGaA, Germany). 


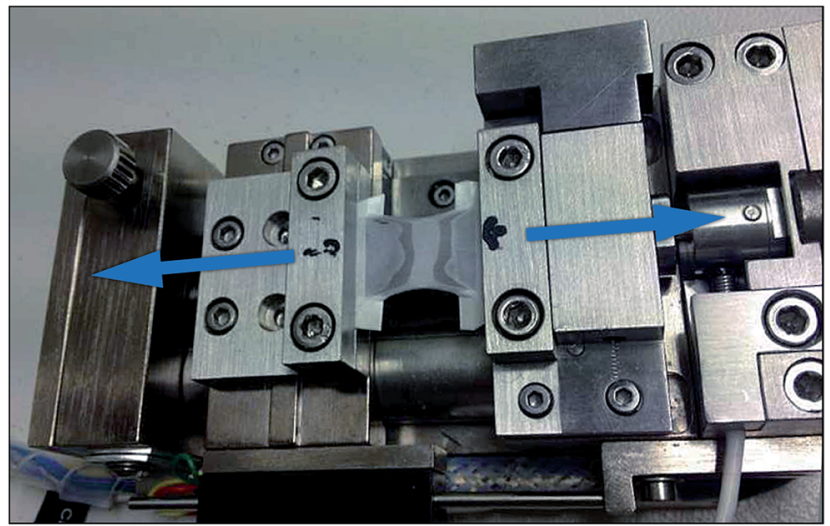

Fig. 1 Photograph of the micromechanical tensile stage with mounted PET fibres (at ca. 100\% strain) according to the Template Transfer Method (TTM). ${ }^{19}$

Once secured in the tensile stage, the side panels of the window were cut (while leaving the fibres intact). The length, width, and thickness of a piece of PET bottle was measured and weighed and the density of the PET was determined to be $1.37 \mathrm{~g} \mathrm{~cm}^{-3}$. This value was in agreement with the previously reported density of bottle-grade PET (which is also close to that of amorphous PET) ${ }^{21}$ and was used to calculate the thickness of the fibre mats after electrospinning, i.e. by weighing a known area of the fibre mat taken adjacent to the template on the collection drum. The tensile strength was taken as the highest stress supported during the test, the Young's modulus was taken as the initial linear slope of the stress-strain curve and the toughness was calculated as the total area under the stress-strain curve.

\section{Determination of fibre size and morphology}

Using detailed scanning electron micrographs, 200 fibres were measured from each spun sample of aligned and unaligned fibres. The angular deviation of aligned fibres was calculated from a minimum of 50 fibres from each spun sample. For these measurements, a Hitachi S-4800 cold-field-emission scanning electron microscope (FE-SEM) was used in conjunction with a thin Pt/Pd 60/40 coating, (10 s at $80 \mathrm{~mA}$ ) in a Cressington 208HR high-resolution sputter.

The molecular draw ratio of each aligned fibre mat $\left(20 \times 20 \mathrm{~mm}^{2}\right.$ cut-outs) was evaluated from their shrinkage upon heating to $150{ }^{\circ} \mathrm{C}$, over a temperature-controlled aluminium surface.

\section{Infra-red spectroscopy (IR)}

All IR spectroscopy measurements were performed on a PerkinElmer Spectrum 2000 using a $1 \mathrm{~cm}^{-1}$ scan step and a single reflection attenuated total reflectance stage (ATR) MKII Golden Gate unit.

\section{X-ray diffraction (XRD)}

The electrospun samples were prepared as thick sample discs to obtain the highest possible diffraction intensity, i.e. by compressing the fibres in a Specac circular dye (diameter $10 \mathrm{~mm}$ ) for $1 \mathrm{~min}$ and $100 \mathrm{kN}$ at room temperature. X-ray diffractograms on samples were taken at room temperature using a PANalytical X'pert Pro MPD diffractometer with a $\mathrm{Cu}-\mathrm{K} \alpha$ source (wavelength $1.5418 \AA$ ) at a step size of $1 \operatorname{arcmin}(2 \theta)$ and scan step time of $51 \mathrm{~s}$.

\section{Differential scanning calorimetry (DSC)}

Thermograms of fibres were obtained with a temperature- and energy-calibrated Mettler-Toledo DSC1. Each sample was weighed at $2.0 \pm 0.1 \mathrm{mg}$, enclosed in a $100 \mathrm{~mL}$ standard aluminium crucible with one hole in the cover. The samples were heated from $30^{\circ} \mathrm{C}$ to $300{ }^{\circ} \mathrm{C}$ at a rate of $10{ }^{\circ} \mathrm{C} \mathrm{min}^{-1}$ under a nitrogen atmosphere at a gas flow rate of $50 \mu \mathrm{L} \mathrm{min}{ }^{-1}$, and allowed to rest for $5 \mathrm{~min}$ before subsequent cooling at $10{ }^{\circ} \mathrm{C}$ $\mathrm{min}^{-1}$. The degree of crystallinity $\left(X_{\mathrm{c}, \mathrm{DsC}}\right)$ was calculated, under the assumption that the morphology of amorphous regions before cold crystallisation and after melting are the same, from the equation: $:^{22}$

$$
X_{\mathrm{c}, \mathrm{DSC}}=\left(\Delta H_{\mathrm{f}}-\Delta H_{\mathrm{c}}\right) / \Delta H_{\mathrm{f}}^{0}
$$

where $\Delta H_{\mathrm{f}}$ is the enthalpy of fusion, $\Delta H_{\mathrm{c}}$ is the enthalpy of cold crystallization, assessed directly from DSC thermograms, and $\Delta H_{\mathrm{f}}^{0}\left(136 \mathrm{~J} \mathrm{~g}^{-1}\right)$ is the enthalpy of fusion of $100 \%$ crystalline PET. $^{23}$

\section{Smoke filtration}

To determine the smoke filtering properties of the fibre mats with different fibre diameters, the mats were evaluated by securing them over a glass tube ( $9 \mathrm{~mm}$ diameter) fitted within a tubular system for smoke transportation and testing (see Fig. 7c). A cigarette (Marlboro Gold, Philip Morris International) with its filter removed was fitted into the other end of the glass tube at a distance of $25 \mathrm{~mm}$ from the fibre mat. The specific surface area of each filter was calculated from the measured average diameter (from SEM) of the fibres. IR-spectroscopy was employed to determine what sort of components were absorbed, small amounts of smoke were used for this purpose, i.e. $2 \mathrm{~mL}$ of smoke was passed through each mat for each $\mu \mathrm{g}$ of fibre mat present, at a rate of $c a .100 \mathrm{~mL} \mathrm{~s}^{-1}$. The filtration capacity was measured gravimetrically as the total mass uptake after exposure to an excess of cigarette smoke ( $1000 \mathrm{mg}$ of tobacco for each $\mathrm{mg}$ of filter), a comparison to the commercial filter tip used in the original cigarette was made using the same proportions of tobacco to filter.

\section{Results and discussion}

\section{Morphology and composition of electrospun recycled PET- fibres}

Fig. 2a-c shows the result of increasing the concentration of PET in the solvent carrier. By adjusting the concentration, the average fibre diameter could be precisely controlled, while the fibre morphologies were almost unaffected and showed continuous long fibres with smooth surfaces. The insets in the 

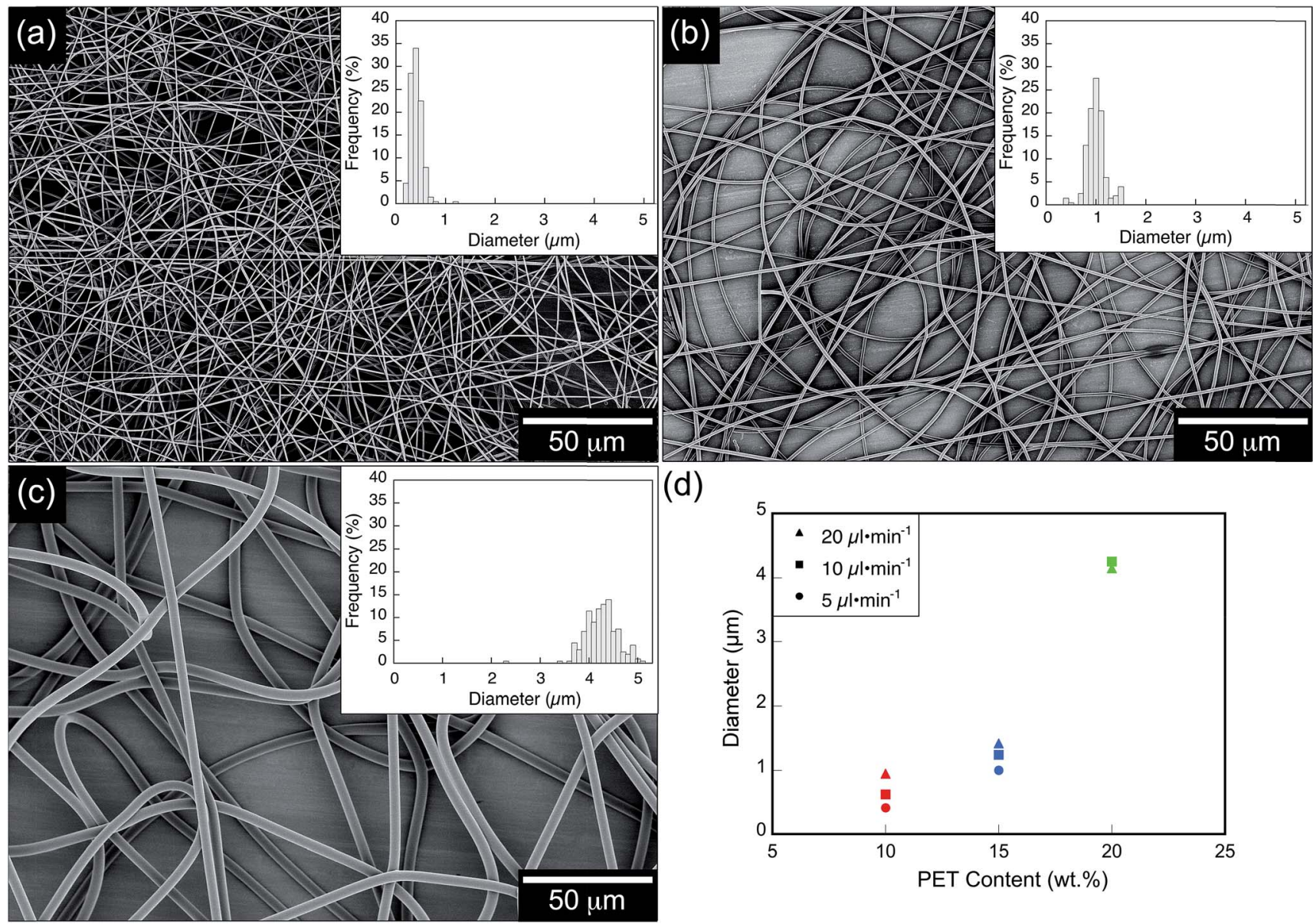

(d)

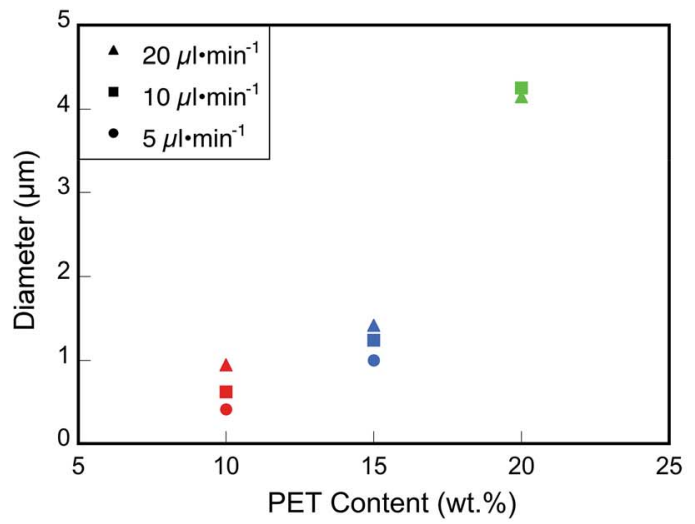

Fig. 2 Electron micrographs show the un-aligned electrospun fibres spun from solutions with different concentrations of PET (a): 10, (b): 15, (c):

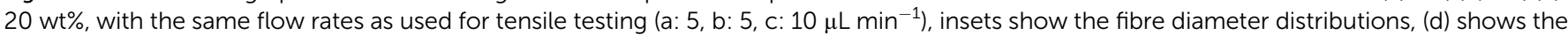
average fibre diameter spun at different flow rates $\left(\mu \mathrm{L} \mathrm{min}^{-1}\right)$ as a function of PET concentration in the electrospinning solutions.

micrographs show the size distribution of the fibres, obtained by measuring the diameters of at least 200 fibres for each sample. The average fibre diameters at these flow rates increased from $0.41 \mu \mathrm{m}( \pm 0.12 \mu \mathrm{m}$, i.e. $\pm 30 \%)$ at $10 \mathrm{wt} \%$, to $1.0 \mu \mathrm{m}( \pm 0.19 \mu \mathrm{m}$, i.e. $\pm 19 \%)$ at $15 \mathrm{wt} \%$, to $4.3 \mu \mathrm{m}( \pm 0.34 \mu \mathrm{m}$, i.e. $\pm 8 \%)$ at $20 \mathrm{wt} \%$ PET. The relative standard deviation was largest for the thinner fibres and decreased with increasing fibre thickness, possibly due to the lower viscosity and high surface tension of the electrospun solutions for these samples, as previously reported. ${ }^{24}$ Fig. $2 \mathrm{~d}$ shows the relationship between the fibre diameter and the PET concentration at different flow rates. A flow rate three times as high (at a given concentration) had only a marginal effect on the thickness of the fibres. For all the evaluated formulations and flow rates, the fibres with greatest uniformity were always prepared at the lowest spinnable flow rate $\left(5 \mu \mathrm{L} \mathrm{min}{ }^{-1}\right.$ for 10 and $15 \mathrm{wt} \%$ PET, $10 \mu \mathrm{L} \mathrm{min}{ }^{-1}$ for $20 \mathrm{wt} \%$ PET), Fig. 2a-c. For ease of reference, the above fibres are hereafter referred to by their approximate diameters: $0.4,1.0$ and $4.3 \mu \mathrm{m}$.

Fig. 3 shows the acquired fibre IR-spectra for the electrospun fibres together with the original bottle PET. The analysis was made to also ensure complete TFA/DCM evaporation in all samples (only $1.0 \mu \mathrm{m}$ fibres are shown). The four major peaks associated with the inherent structure of the polyethylene terephthalate were the terephthalic acid ester $\mathrm{C}=\mathrm{O}$ group at $1714 \mathrm{~cm}^{-1}$, the asymmetric $\mathrm{C}-\mathrm{C}-\mathrm{O}$ and the $\mathrm{O}-\mathrm{C}-\mathrm{C}$ stretching at

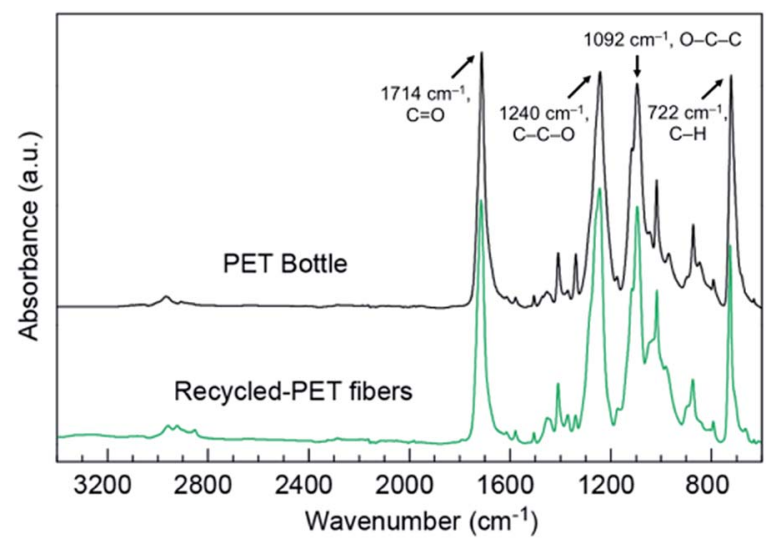

Fig. 3 IR-spectra of the $1.0 \mu \mathrm{m}$ thick electrospun PET fibres and of the original PET bottle. The fibres were analysed 30-60 min after electrospinning to ensure that no solvent remained after this time period, i.e. prior to performing other measurements. All electrospun fibres showed the same IR-spectra. 
1240 and $1092 \mathrm{~cm}^{-1}$, respectively, and the $\mathrm{C}-\mathrm{H}$ wagging vibrations from the aromatic structures at $722 \mathrm{~cm}^{-1}$. Trifluoroacetic acid would, if present, be visible within the $1250-1180 \mathrm{~cm}^{-1}$ region due to the $\mathrm{C}-\mathrm{F}$ stretching modes $(1244,1240$ and $\left.1199 \mathrm{~cm}^{-1}\right),{ }^{25}$ whereas the dichloromethane $\mathrm{C}-\mathrm{Cl}$ symmetric and asymmetric stretching should appear at 874 and $771 \mathrm{~cm}^{-1}$. Among these peaks, only those of 1199,874 and $771 \mathrm{~cm}^{-1}$ could be used to assess trace solvents remaining in the prepared fibre mats, due to the overlapping nature of the remaining peaks. However, none of these peaks showed any significant difference from those of the spectra for the PET samples cut from the original bottle. This PET bottle displayed a minor peak at $1340 \mathrm{~cm}^{-1}$ and a slightly smaller intensity of the peaks in the $3100-2800 \mathrm{~cm}^{-1}$ region.

In summary, the electrospinning from solution allowed the regeneration of the PET polymer as $0.4,1.0$ and $4.3 \mu \mathrm{m}$ thick continuous fibres without any trapped solvent phases or apparent degradation of the original material.

\section{Tensile testing}

Tensile testing was conducted on all the prepared fibres as aligned fibre mats, shown in Fig. 4. The fibres had an average angular deviation of $12.4^{\circ}$, as concluded from FE-SEM analysis. As the fibre diameter decreased, an increase in strength and in Young's modulus was observed. This could be explained by a higher degree of molecular alignment when thinner fibres were produced in the electrical field, due to the increased fibre stretching. ${ }^{26}$ The strain at break is usually reduced when the strength and modulus increase, but, the results contradicted this trade-off with a positive correlation between strength and strain at break, as shown in Fig. 4, i.e. the strongest fibres also had the highest strain at break. Of the different fibres tested, the $1.0 \mu \mathrm{m}$ fibres showed the best combination of mean tensile strength (62.5 MPa), modulus (1.39 GPa) and toughness (65.5 $\mathrm{MJ} \mathrm{m}^{-3}$ ), Fig. 4. The $0.4 \mu \mathrm{m}$ fibres had a similar strength and a higher modulus, but a significantly lower elongation at

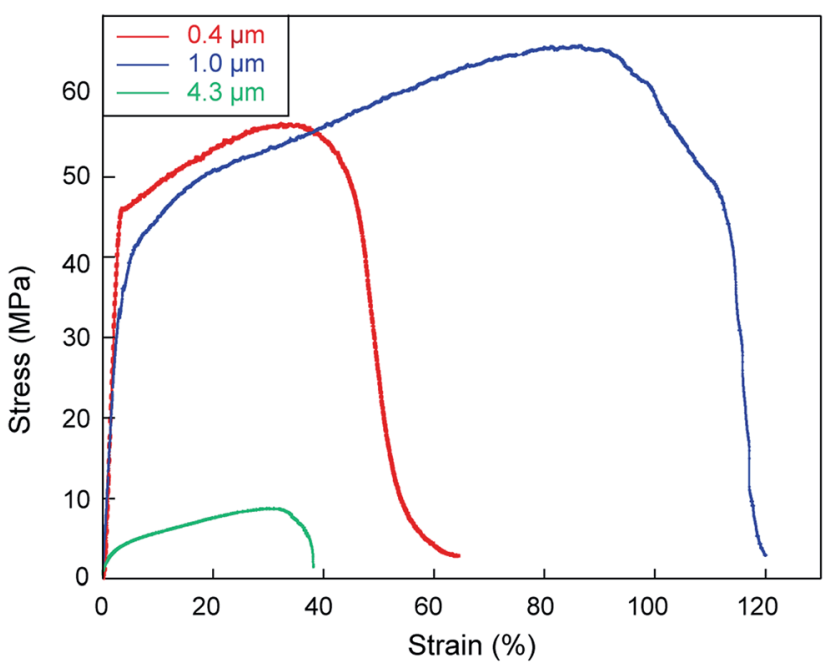

Fig. 4 Tensile stress-strain curves for the $0.4,1.0$ and $4.3 \mu \mathrm{m}$ fibre mats. break. The fibres with a diameter of $4.3 \mu \mathrm{m}$ had a much lower tensile strength $(-87 \%)$, lower modulus $(-89 \%)$ and lower toughness $(-97 \%)$, than the $1.0 \mu \mathrm{m}$ fibres, Fig. 5 .

A comparison between the $1.0 \mu \mathrm{m}$ fibres (i.e. low density fibre mats) and that of bottle-grade PET (tensile strength of $c a$. $79 \mathrm{MPa}$, Young's modulus of $c a .2 .8 \mathrm{GPa}$ and elongation at break of $c a .70 \%)^{27}$ showed that the $1.0 \mu \mathrm{m}$ fibres had only marginally lower strength and modulus but a significantly higher strain at break, i.e. a higher toughness. The toughness of the fibre mats was comparable to that of amorphous biaxially oriented films of PET, pre-drawn to a draw ratio of $c a .3-4 .^{28}$

Veleirinho et al. ${ }^{6}$ measured the mechanical properties along only lightly oriented electrospun fibre mats (spun virgin PET and by using the same solvent ratios as in the present study) with fibre diameters of $c a .0 .6 \mu \mathrm{m}$. The stiffness, strength and extensibility (strain at break) were, respectively, 50-60 MPa, 1-2 MPa and 20-40\%. These properties were significantly lower than those of the present fibre mats, showing the importance of fibre alignment when evaluating the fibre properties. Commercial single melt-spun PET filaments without additional post-drawing have a stiffness, strength and extensibility on the order of 2-14 GPa, 170-550 MPa and 45-300\%. ${ }^{29,30}$ Post-drawn PET have been reported to have a stiffness and strength of $15 \mathrm{GPa}$ and $1100 \mathrm{MPa}$, but at the expense of much inferior extensibility when compared to the present fibres. ${ }^{31}$ Hence the conclusion from this comparison is that electrospinning PET at the present conditions does not create the same amount of high molecular orientation as in the strongest commercially post-

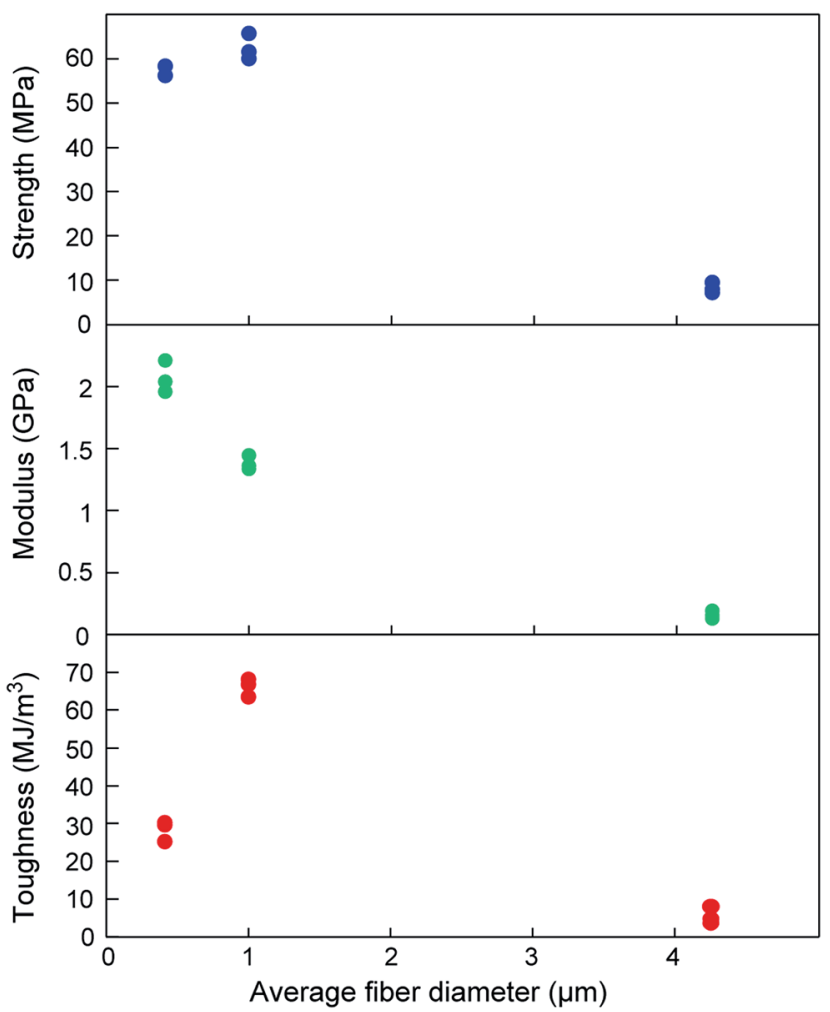

Fig. 5 The mechanical properties of the $0.4,1.0$ and $4.3 \mu \mathrm{m}$ fibre mats as a function of average fibre diameter. 
drawn fibres. Instead the mechanical properties of the present as-spun fibre are comparable with as-spun single PET fibre filaments.

\section{Crystal structure and molecular morphology (XRD and DSC)}

Fig. 6a shows X-ray diffractograms of the PET bottle and the electrospun fibre mats. Semi-crystalline PET typically shows characteristic crystalline XRD-peaks at $2 \theta=16.1,17.5,21.5$, $22.7,24.0,26.1,27.8$, and $32.5^{\circ}$, corresponding to the: $0 \overline{1} 1,010$, $\overline{1} 11, \overline{1} 10,011,100,021,002,1 \overline{1} 1$ and 101 crystal planes, ${ }^{23}$ and a broad amorphous halo at $10-35^{\circ} \cdot{ }^{32-34}$ As seen in Fig. 6a, the diffractogram of the PET bottle showed only one relatively wide single diffraction peak at $25.5^{\circ}$, corresponding to the (100) crystal plane, together with an amorphous halo at slightly lower angles. Nunes et al. $^{34}$ ascribed this particular semi-crystalline structure of PET bottles to the biaxial molecular orientation achieved in the bottle wall during blow moulding. The electrospun fibres displayed broader halos with centres at $22-23^{\circ}$ and the absence of the peak at $25.5^{\circ}$, indicating that they consisted mainly of amorphous material. Hadjizadeh et al. ${ }^{33}$ reported a similar lack of crystallinity in electrospun samples and attributed this to the rapid solidification of stretched PET chains. The
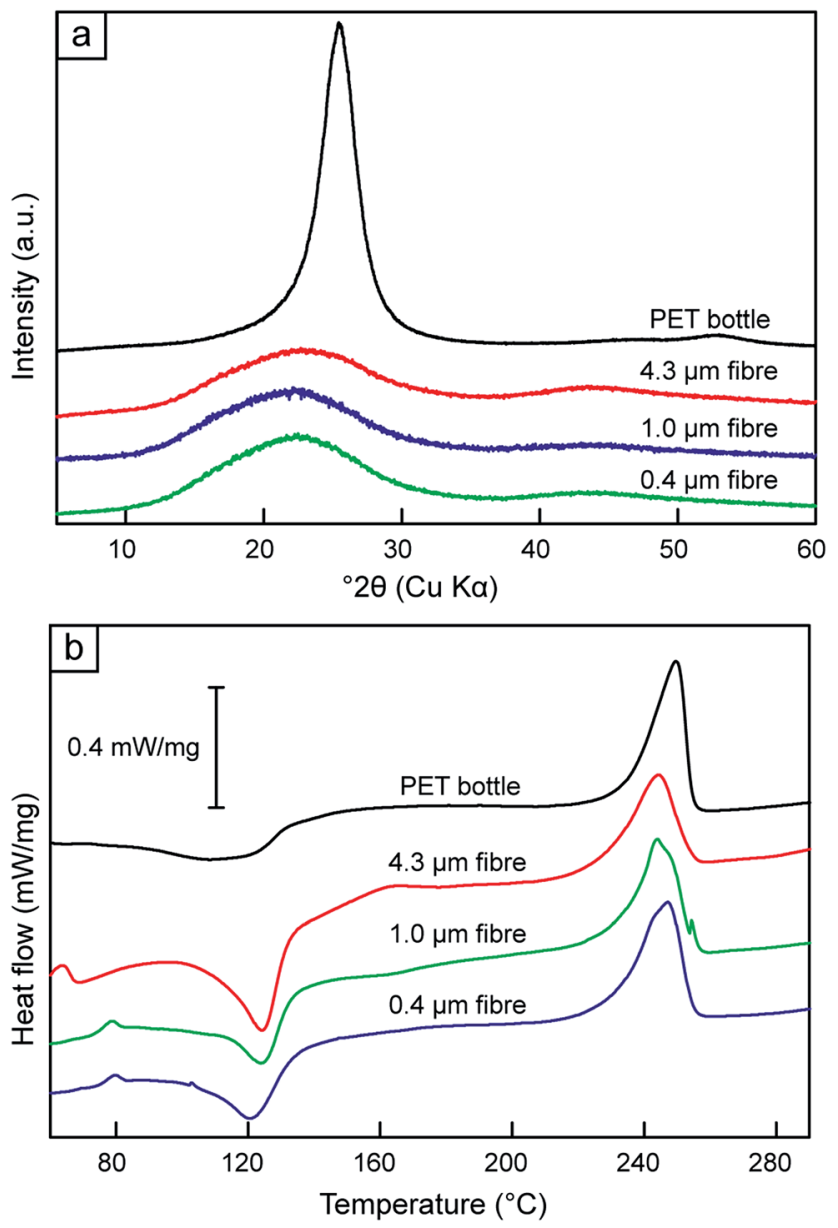

Fig. 6 X-ray diffractograms (a) and DSC thermograms (b) for the original PET bottle and fibres spun to different diameters. solidification rate at the conditions used in the present study was ca.1-10 milliseconds, which is much shorter than the time frame of $c a .50 \mathrm{~s}$ required for the crystallization of PET at a cooling rate of $100{ }^{\circ} \mathrm{C} \min ^{-1} \cdot{ }^{35}$ However, it is also known that PET can form a mesomorphic phase (oriented amorphous phase) which does not reveal itself clearly in the diffractograms. ${ }^{36}$ The formation of an oriented mesomorphic phase inside electrospun PET fibres has also been proposed by Wang et $a .^{24}$ Keum et al. showed that the presence of this oriented amorphous phase reveals itself as a skew in the amorphous halo. ${ }^{37}$ This sort of skewed (unsymmetrical) amorphous halo was most noticeable in the case of the 0.4 and the $1.0 \mu \mathrm{m}$ fibres, as can be seen in Fig. 6 a.

The existence of an oriented molecular morphology inside the fibres was verified by a shrinkage test, where the different fibre mats were heated to a temperature of $150{ }^{\circ} \mathrm{C}$. The shrinkage in the fibre direction was $54 \%$ for the $0.4 \mu \mathrm{m}$ and $43 \%$ for the $1.0 \mu \mathrm{m}$ fibres, whereas the shrinkage for the $4.3 \mu \mathrm{m}$ fibres was only ca. 4\% (Table 1). This confirmed that there was a molecular orientation, since shrinkage of $54 \%$ in the fibre direction would require an initial molecular draw ratio of 2.2 or more, and complete relaxation could not be expected due to molecular hysteresis. Similar draw ratios have previously been observed in other electrospun polymers, measured by infra-red dichroism spectroscopy. ${ }^{38}$

The existence of a mesomorphic phase in the two thinnest fibres was further verified by the DSC analysis. Fig. $6 \mathrm{~b}$ shows the heating thermograms of the PET bottle and the electrospun fibres with diameters from $0.4 \mu \mathrm{m}$ to $4.3 \mu \mathrm{m}$. No significant difference in crystallisation temperature during heating $\left(122 \pm 2{ }^{\circ} \mathrm{C}\right)$ or melting point $\left(247 \pm 3{ }^{\circ} \mathrm{C}\right)$ could be observed between the fibre samples and the original PET bottle. The glass transition temperature $\left(T_{\mathrm{g}}\right)$ and degree of apparent crystallinity $\left(X_{\mathrm{c}, \mathrm{DSC}}\right)$ as calculated by eqn (1), did however show significant differences for the different samples, see Table 1.

The fibre mats consisting of $0.4 \mu \mathrm{m}$ and $1.0 \mu \mathrm{m}$ diameter fibres showed the highest $T_{\mathrm{g}}\left(80.5-81.0{ }^{\circ} \mathrm{C}\right.$, Table 1$)$. This higher $T_{\mathrm{g}}$ was consistent with a more constrained/stretched amorphous phase, and the much greater shrinkage observed when these fibres were heated..$^{39}$ On the other hand, the $4.3 \mu \mathrm{m}$ fibres showed a $T_{\mathrm{g}}$ of only $66.4{ }^{\circ} \mathrm{C}$, which was consistent with almost no shrinking (3.6\%) of these fibres. The thermogram of the PET bottle (Fig. 6b) showed no clear glass transition due to the smaller amount of amorphous material in the original PET bottle which had a $21.2 \%$ crystalline content.

Table 1 Thermal properties and shrinkage upon heating for the $\mathrm{PET}^{a}$

\begin{tabular}{llcl}
\hline Sample & $T_{\mathrm{g}}\left({ }^{\circ} \mathrm{C}\right)$ & $X_{\text {c,DSC }}(\%)$ & Shrinkage $(\%)$ \\
\hline PET bottle & N/A & 21.2 & $11(\|), 41(\perp)$ \\
Fibre $0.4 \mu \mathrm{m}$ & 81.0 & 7.9 & 54 \\
Fibre $1.0 \mu \mathrm{m}$ & 80.5 & 6.0 & 43 \\
Fibre $4.3 \mu \mathrm{m}$ & 66.4 & 0.2 & 3.6
\end{tabular}

${ }^{a}$ The data show shrinkage in the fibre direction and for the original bottle, parallel $(\|)$ and perpendicular $(\perp)$ to the height of the bottle. 
The $4.3 \mu \mathrm{m}$ fibres showed no significant crystallinity $(0.2 \%)$, whereas the 0.4 and $1.0 \mu \mathrm{m}$ fibres showed an apparent degree of crystallinity of $6-8 \%$, Table 1 . The inconsistency with the X-ray diffractograms in Fig. 6a stems from the fact that eqn (1) assumes that the amorphous morphology before crystallisation and after melting are the same. This was not the case for the 0.4 and $1.0 \mu \mathrm{m}$ fibres, since they initially contained a highly oriented amorphous morphology, i.e. a mesomorphic phase, and the change in enthalpy to the crystalline phase was thus less than that of an un-oriented amorphous material (e.g. the $4.3 \mu \mathrm{m}$ fibres). On the macroscopic scale, this can be interpreted as meaning that there were local regions, smaller than the detection limit of XRD (ca. $3 \mathrm{~nm}),{ }^{39-42}$ with a greater ordering of PET molecules than in the completely amorphous counterpart. None of the fibres contained any conventional PET crystals and they were considered to be completely amorphous. However, in the case of the two thinnest fibres, a large degree of molecular orientation existed, which was higher than the molecular orientation in the commercial semi-crystalline PET bottle.

\section{Influence of molecular morphology on mechanical properties}

The higher modulus and tensile strength of the two thinnest fibres $(0.4$ and $1.0 \mu \mathrm{m})$, than of the $4.3 \mu \mathrm{m}$ fibres was attributed to the greater amount of local regions with intensified intermolecular interactions due to the oriented mesomorphic phase, diverting a larger portion of the stress to the stronger covalent backbone of the polymer. This explanation was consistent with the largest shrinkage for the $0.4 \mu \mathrm{m}$ fibres upon heating (54\%, Table 1), and the high Young's modulus which exceeded that of all the other fibres (2.1 GPa, Fig. 5). The more extensive initial molecular orientation due to the larger draw ratio for the $0.4 \mu \mathrm{m}$ fibres also explained the reduced strain at break of these fibres compared with that of the $1.0 \mu \mathrm{m}$ fibres. Extensive molecular stretching is known to lower the strain at break. The most prominent example of this is probably the drawing and preparation of ultra-high-molecular-weight polyethylene fibres (Spectra ${ }^{\circledR}$ fibres), which show only a fraction of the strain at break of the un-stretched material. ${ }^{43}$

\section{Smoke filtration}

Fig. 7a and $\mathrm{b}$ show one of the electrospun fibre mats before and after smoke filtration. The filtration capabilities of the mats were tested using a cigarette as the smoke source. The fibre mat/ membrane was secured inside the tubular system according to Fig. 7c. The air/smoke flow was controlled via a flow rate valve (not shown) and was adjusted to expose the fibre mats to the same amount of smoke ( $2 \mathrm{~mL}$ of smoke per $\mu \mathrm{g}$ of fibre mat, at $\left.100 \mathrm{~mL} \mathrm{~min}^{-1}\right)$. The fibre mats turned brown immediately when subjected to the smoke (see ESI $\dagger$ ), and although the effectiveness of the filtration was obvious to the naked eye (Fig. 7b), additional IR spectroscopy measurements were made, see Fig. $7 \mathrm{~d}$. All the spectra were normalized to the absorbance of the characteristic PET bands (Fig. 3). A substantial increase in the IR-absorbance of the mat after the smoke filtration occurred in the $3000-2850 \mathrm{~cm}^{-1}$ range, corresponding to $\mathrm{C}-\mathrm{H}$ stretching. This $\mathrm{C}-\mathrm{H}$ stretching can be related to the many carcinogenic hydrocarbons that exist in tobacco smoke. ${ }^{16}$ The additional hump shown in the $3500-3200 \mathrm{~cm}^{-1}$ region corresponds to the $\mathrm{O}-\mathrm{H}$ stretching (possibly also $\mathrm{N}-\mathrm{H}$ stretching) characteristic of alcohols, hundreds of which are identified in tobacco smoke and possibly contribute in tumorigenesis. ${ }^{16}$ Overall the absorption of these hydrocarbons/alcohols increased as the fibre diameter decreased, i.e. when the specific surface area (SSA) increased. The SSA for each membrane was calculated by assuming smooth and long cylindrical fibres, shown in Table 2.

The filtration capacities of the electrospun PET membranes were further evaluated by measuring the total mass uptake when a large excess of cigarette smoke was passed through each
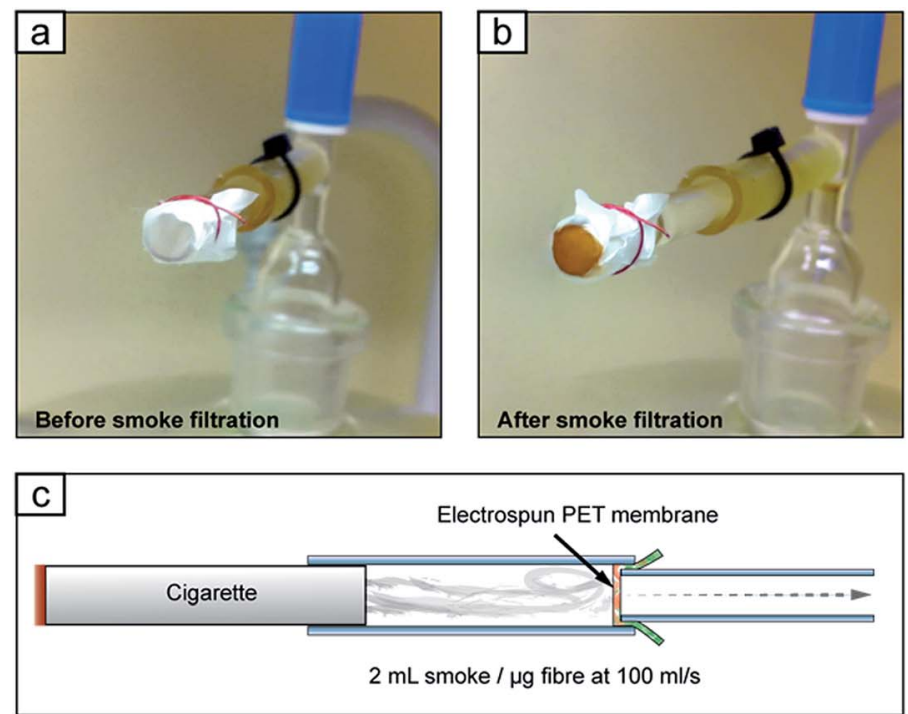

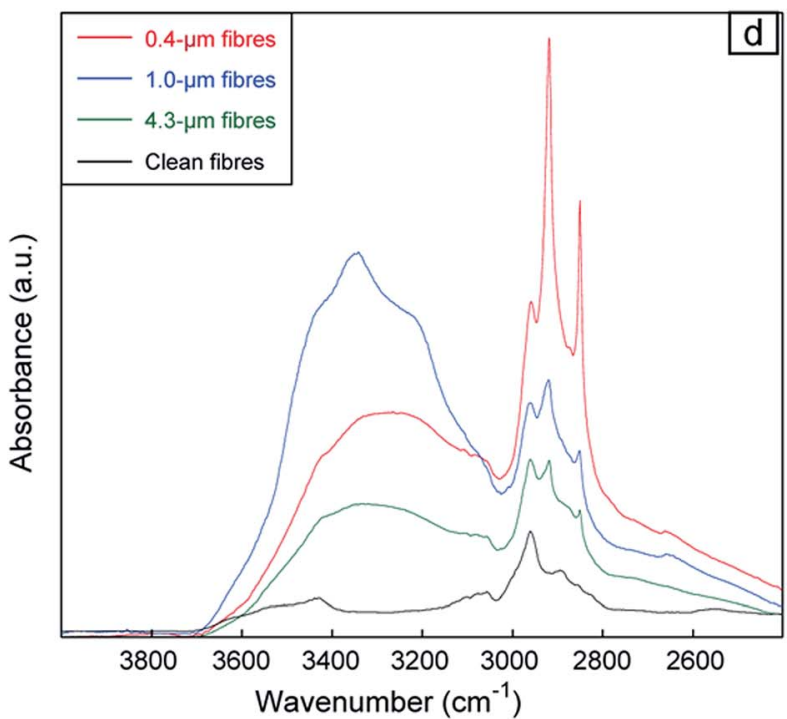

Fig. 7 Photographs of fibre mats (a) before and (b) after smoke filtration testing ( $1.0 \mu \mathrm{m}$ diameter), conducted according to the scheme shown in (c). IR-spectroscopy (d) of a clean fibre mat compared to that of smoke-exposed fibre mats with average fibre diameters of $0.4,1.0$ and $4.3 \mu \mathrm{m}$. 
Table 2 Filtration capacity of the electrospun PET filter membranes compared to the original cigarette filter tip ${ }^{a}$

\begin{tabular}{llccc}
\hline Fibre diameter & Specific surface area & Rel. mass uptake & Rel. mass uptake (after drying) & Volatile fraction \\
\hline $0.4 \mu \mathrm{m}$ & $7.07 \mathrm{~m}^{2} \mathrm{~g}^{-1}$ & 43.7 & 41.5 & 0.049 \\
$1.0 \mu \mathrm{m}$ & $2.90 \mathrm{~m}^{2} \mathrm{~g}^{-1}$ & 32.9 & 30.7 & 0.067 \\
$4.3 \mu \mathrm{m}$ & $0.67 \mathrm{~m}^{2} \mathrm{~g}^{-1}$ & 26.4 & 23.1 & 0.126 \\
Original filter tip & $0.10 \mathrm{~m}^{2} \mathrm{~g}^{-1}$ & 2.7 & 2.0 & 0.252
\end{tabular}

${ }^{a}$ A large excess of burnt cigarette smoke was passed through each fibre mat. Mass uptakes are relative to the initial fibre mat weight. The fraction of volatile components is relative to the total mass of all absorbed substances.

filter. The results verified that the thinner fibres $(0.4 \mu \mathrm{m})$ contained the highest amount of absorbed smoke components (43.7 times its own weight, Table 2), the fibre mat weightincrease was ca. 2 times higher than that seen for the $4.3 \mu \mathrm{m}$ fibres (absorbed 26.4 times its own weight). Small amounts of volatile components were absorbed in all the filters (e.g. water), which revealed themselves when drying the membranes in vacuum for $>3 \mathrm{~h}$. The amount of evaporated volatile components in the thickest fibres $(4.3 \mu \mathrm{m})$, was $12.6 \mathrm{wt} \%$ of the total absorbed mass, whereas the absorbed substances in the $0.4 \mu \mathrm{m}$ fibres contained only $4.9 \mathrm{wt} \%$ volatiles.

The original cellulose acetate cigarette filter tip absorbed only 2.7 times its own weight during the same treatment. In addition to the inferior filtration capacity, these much thicker fibres absorbed a larger portion of volatiles, $25.2 \mathrm{wt} \%$ of the absorbed matter. This can be interpreted as if the fibre mats with thick fibres and thus larger pores, had a much lower capability of trapping small solid/non-volatile particles.

\section{Conclusions}

Solution-electrospinning has been used to prepare the thinnest ever reported PET fibres obtained from recycled PET. The thermal (DSC) and the IR characteristics of the polymer were the same before and after electrospinning, neither showed any evidence of degradation in the electrospun fibres. The average fibre diameter was varied by over one order of magnitude (from $0.4 \mu \mathrm{m}$ to $4.3 \mu \mathrm{m}$ ) by adjusting the concentration of recycled PET in the electrospinning solutions. The uniformity of the fibres depended on the feed rate of the solutions, the most uniform fibres being formed at the slowest rates. A template transfer method (TTM) was applied to carry out micromechanical tensile testing on aligned fibre mats, and it was found that the strength, strain at break, and modulus increased as the fibre diameter decreased. This resulted in a large increase in toughness of the fibres, making them useful for filtration applications. The $1.0 \mu \mathrm{m}$ thick PET fibres displayed high strength, a high modulus and high toughness $(62.5 \mathrm{MPa}$, $1.39 \mathrm{GPa}$ and $65.5 \mathrm{MJ} \mathrm{m}^{-3}$ ). The improvement in the mechanical properties originated from the formation of a completely amorphous mesomorphic phase with highly oriented PET molecules, as a result of the extensive fibre stretching and the rapid solidification of the fibres during the spinning. The molecular draw ratio was greater than 2.2 for the thinnest fibres, which was higher than that in the original PET bottle. The fibre mats were evaluated as filtration devices for air filtration of condensing hydrocarbons and particulate matter. Tobacco smoke was chosen as a model substance as it contains thousands of different particulate and vapour phase substances. IR-analysis confirmed an increased absorption efficiency of hydrocarbons and alcohols as the fibre diameter decreased. Gravimetrical measurements also showed an increased filtration capacity (especially of non-volatile particles) with decreased fibre diameter. A filtration capacity of more than 43 times the filters own weight was seen for filters with an average fibre diameter of $0.4 \mu \mathrm{m}$, which is significantly higher than shown for the original cigarette filter tip.

The combination of the large-scale availability of recycled PET, the electrospinning-induced formation of a toughnessenhancing internal morphology yielding $c a$. 30 times tougher fibre mats, and the high affinity of these PET fibre mats for airborne hydrocarbons, also open the way for the applied use of recycled PET in a range of industrial filters. In the future we foresee that these recyclable electrospun non-woven filters develop into biodegradable materials that not only show specific absorption characteristics but also with a tailored lifespan for the intended application, e.g. materials based on biopolyesters.

\section{Acknowledgements}

The UIUC Department of Chemical and Biomolecular Engineering is acknowledged for the collaborative exchange program between KTH and the University of Illinois at UrbanaChampaign. Sara Blomqvist, Samer Nameer and Amelie Hållberg are acknowledged for their assistance in the prescreening of different solvent combinations.

\section{Notes and references}

1 U.S. Environmental Protection Agency, Wastes - Resource Conservation - Common Wastes \& Materials - Plastics, http://www.epa.gov/osw/conserve/materials/plastics.htm, accessed 03 September 2014.

2 V. Jankauskaité, G. Macijauskas and R. Lygaitis, J. Mater. Sci., 2008, 14, 119-127.

3 F. Welle, Resour., Conserv. Recycl., 2011, 55, 865-875.

4 I. Grishenko, Polyethylene terephthalate weekly price report 13 January 2012, ICIS Report 13.01.2012, Reed Elsevier, London, 2012.

5 A. Oromiehie and A. Mamizadeh, Polym. Int., 2004, 53, 728732. 
6 B. Veleirinho, M. F. Rei and J. A. Lopes-Da-Silva, J. Polym. Sci., Part B: Polym. Phys., 2008, 46, 460-471.

7 G. Li, Y. Zhao, M. Lv, Y. Shi and D. Cao, Colloids Surf., A, 2013, 436, 417-424.

8 F. Awaja and D. Pavel, Eur. Polym. J., 2005, 41, 1453-1477.

9 H. Rajabinejad, R. Khajavi, A. Rashidi, N. Mansouri and M. E. Yazdanshenas, Int. J. Environ. Res. Public Health, 2009, 3, 663-670.

10 R. D. Anandjiwala and L. Boguslavsky, Text. Res. J., 2008, 78, 614-624.

11 M. A. S. Spinacé and M. A. De Paoli, J. Appl. Polym. Sci., 2001, 80, 20-25.

12 C. L. Beyler and M. M. Hirschler, SFPE handbook of fire protection engineering, 2002, vol. 2 .

13 C. J. Thompson, G. G. Chase, A. L. Yarin and D. H. Reneker, Polymer, 2007, 48, 6913-6922.

14 Y. Cai, H. Ke, T. Zhang, J. Dong, H. Qiao, H. Wang, Z. Xu, Q. Wei, Y. Zhao and H. Fong, Polym. Polym. Compos., 2011, 19, 773-780.

15 P. Čupr, Z. Flegrová, J. Franců, L. Landlová and J. Klánová, Environ. Int., 2013, 54, 26-34.

16 R. L. Stedman, Chem. Rev., 1968, 68, 153-207.

17 J. Phillips, B. Kluss, A. Richter and E. Massey, ATLA, Altern. Lab. Anim., 2005, 33, 239-248.

$18 \mathrm{Z}$. Li and C. Wang, in One-dimensional nanostructures, Springer Berlin Heidelberg, 2013, ch. 2, pp. 15-28.

19 R. L. Andersson, M. Salajkova, P. E. Mallon, L. A. Berglund, M. S. Hedenqvist and R. T. Olsson, J. Polym. Environ., 2012, 20, 967-975.

20 R. L. Andersson, A. Martínez-Abad, J. M. Lagaron, U. W. Gedde, P. E. Mallon, R. T. Olsson and M. S. Hedenqvist, Int. J. Mol. Sci., 2014, 15, 15912-15923.

21 T. Uchiyama, M. Suyama, M. M. Alam, T. Asano, S. Henning, A. Flores, F. J. Baltá Calleja and M. F. Mina, Polymer, 2007, 48, 542-555.

22 Y. Kong and J. N. Hay, Polymer, 2002, 43, 3873-3878.

23 H. W. Starkweather, P. Zoller, G. A. Jones and A. J. Vega, J. Polym. Sci., Polym. Phys. Ed., 1982, 20, 751-761.
24 C. Wang, M.-F. Lee and Y.-J. Wu, Macromolecules, 2012, 45, 7939-7947.

25 R. E. Kagarise, J. Chem. Phys., 1957, 27, 519-522.

26 D. Papkov, Y. Zou, M. N. Andalib, A. Goponenko, S. Z. D. Cheng and Y. A. Dzenis, ACS Nano, 2013, 7, 33243331.

27 L. Á. Córdoba, G. Martínez-Barrera, C. B. Díaz, F. U. Nuñez and A. L. Yañez, Int. J. Polym. Sci., 2013, 2013, 6.

28 Y. Rao, J. Greener, C. A. Avila-Orta, B. S. Hsiao and T. N. Blanton, Polymer, 2008, 49, 2507-2514.

29 D. G. Baird and D. I. Collias, Polymer processing - principles and design, John Wiley and Sons, New York, 1998.

30 J. H. Lee, K. S. Lim, W. G. Hahm and S. H. Kim, J. Appl. Polym. Sci., 2013, 128, 1250-1256.

31 J. Yao, C. W. Bastiaansen and T. Peijs, Fibers, 2014, 2, 158186.

32 D. E. Bosley, J. Appl. Polym. Sci., 1964, 8, 1521-1529.

33 A. Hadjizadeh, A. Ajji and M. N. Bureau, J. Mech. Behav. Biomed. Mater., 2011, 4, 340-351.

34 R. A. X. Nunes, V. C. Costa, V. M. d. A. Calado and J. R. T. Branco, Mater. Res., 2009, 12, 121-125.

35 X. Jiang, S. Luo, K. Sun and X. Chen, eXPRESS Polym. Lett., 2007, 1, 245-251.

36 J. K. Keum and H. H. Song, Polymer, 2005, 46, 939-945.

37 J. K. Keum, H.-J. Jeon, H. H. Song, J.-I. Choi and Y.-K. Son, Polymer, 2008, 49, 4882-4888.

38 R. L. Andersson, V. Ström, U. W. Gedde, P. E. Mallon, M. S. Hedenqvist and R. T. Olsson, Sci. Rep., 2014, 4, 6335.

39 U. W. Gedde, Polymer Physics, Springer, 1995.

40 A. M. Pourrahimi, D. Liu, L. K. H. Pallon, R. L. Andersson, A. Martinez Abad, J. M. Lagaron, M. S. Hedenqvist, V. Strom, U. W. Gedde and R. T. Olsson, RSC Adv., 2014, 4, 35568-35577.

41 G. D. Mihai, V. Meynen, M. Mertens, N. Bilba, P. Cool and E. F. Vansant, J. Mater. Sci., 2010, 45, 5786-5794.

42 J. Greener, A. H. Tsou and T. N. Blanton, Polym. Eng. Sci., 1999, 39, 2403-2418.

43 J. Smook, W. Hamersma and A. Pennings, J. Mater. Sci., 1984, 19, 1359-1373. 